\title{
Systematic Investigation of Insulin Fibrillation on a Chip
}

\author{
Hoon Suk Rho ${ }^{1,2}{ }^{-0}$, Henk-Willem Veltkamp ${ }^{3}{ }^{\circledR}$, Alexander Thomas Hanke ${ }^{4}$, Marcel Ottens ${ }^{4}$, \\ Christian Breukers ${ }^{5}$, Pamela Habibović ${ }^{1}$ and Han Gardeniers ${ }^{2, *(1)}$
}

1 Department of Instructive Biomaterials Engineering, MERLN Institute for Technology-Inspired Regenerative Medicine, Maastricht University, 6200 MD Maastricht, The Netherlands; h.rho@maastrichtuniversity.nl (H.S.R.); p.habibovic@maastrichtuniversity.nl (P.H.)

2 Mesoscale Chemical Systems Group, MESA+ Institute for Nanotechnology, University of Twente, 7522 NB Enschede, The Netherlands

3 Integrated Devices and Systems Group, MESA+ Institute for Nanotechnology, University of Twente, 7522 NB Enschede, The Netherlands; h.veltkamp@utwente.nl

4 BioProcess Engineering Group, Department of Biotechnology, Faculty of Applied Sciences, Delft University of Technology, 2628 CD Delft, The Netherlands; athanke@gmail.com (A.T.H.); m.ottens@tudelft.nl (M.O.)

5 Medical Cell BioPhysics Group, Technical Medical Centre, University of Twente, 7522 NB Enschede, The Netherlands; c.breukers@utwente.nl

* Correspondence: j.g.e.gardeniers@utwente.nl; Tel.: +31-(0)53-489-4356

Received: 9 February 2020; Accepted: 17 March 2020; Published: 18 March 2020

\begin{abstract}
A microfluidic protein aggregation device (microPAD) that allows the user to perform a series of protein incubations with various concentrations of two reagents is demonstrated. The microfluidic device consists of 64 incubation chambers to perform individual incubations of the protein at 64 specific conditions. Parallel processes of metering reagents, stepwise concentration gradient generation, and mixing are achieved simultaneously by pneumatic valves. Fibrillation of bovine insulin was selected to test the device. The effect of insulin and sodium chloride $(\mathrm{NaCl})$ concentration on the formation of fibrillar structures was studied by observing the growth rate of partially folded protein, using the fluorescent marker Thioflavin-T. Moreover, dual gradients of different $\mathrm{NaCl}$ and hydrochloric acid $(\mathrm{HCl})$ concentrations were formed, to investigate their interactive roles in the formation of insulin fibrils and spherulites. The chip-system provides a bird's eye view on protein aggregation, including an overview of the factors that affect the process and their interactions. This microfluidic platform is potentially useful for rapid analysis of the fibrillation of proteins associated with many misfolding-based diseases, such as quantitative and qualitative studies on amyloid growth.
\end{abstract}

Keywords: microfluidics; high-throughput screening; insulin fibrillation; dual concentration gradients

\section{Introduction}

Several common neurodegenerative disorders, such as Parkinson's disease, type II diabetes, and Alzheimer's disease, are known to be related to amyloidosis, in which innoxious proteins change into amyloid fibrils [1-4]. Understanding the fundamental mechanism and critical parameters in the formation of amyloid fibrils is critical for developing strategies to interrupt or reverse amyloid fibrillation and treat diseases caused by severe protein conformational misfolding $[4,5]$. The main parameters that affect protein fibrillation are identity, purity, and concentration of protein and environmental factors, such as $\mathrm{pH}$, ionic strength, mechanical agitation, and temperature [5-10]. 
Moreover, transient partially folded proteins are thought to be closely related to fibril formation, e.g., by acting as fibril precursors $[1,7]$.

Insulin is a small protein with a molecular weight of $5.7 \mathrm{kDa}$ that has $\alpha$-helical structures in the native state $[3,11]$. However, the protein converts into amyloid fibrillar structures under appropriate conditions [6]. Insulin is commonly used as a model system to evaluate the mechanism of amyloid aggregation because the structural properties of insulin fibrils are similar to those of other amyloidogenic proteins [11-13]. Previous in vitro studies characterized the influences of temperature, $\mathrm{pH}$, agitation, and ionic strength on the aggregation of insulin through various techniques [5,12-14]. Batch incubation of insulin solution under different conditions is the most common technique to form insulin fibrils in laboratories $[5,7,9]$. Even though the traditional incubation method successfully identified the critical parameters affecting the formation of insulin fibrils and the growth of insulin fibrillar structures, multiple sample preparation steps and long incubation times are required to systematically evaluate the (intertwined) effects of a large number of factors. Besides, the conventional method for the kinetic study of protein fibrillation phenomena is limited to the observations of the early stage growth of fibrils only due to the large sample volume, which requires additional processes to analyze the number of fibrils or fibrillar structures.

To address these challenges, several microfluidic platforms have been developed to study protein-folding processes [2,15-26]. The potential of miniaturized systems for fundamental studies of protein aggregation was shown by the examples of microreactors [2,27], microchannel networks [15,19-21,23,24], and microdroplets $[16-18,22,25,26]$. Laminar flow in microfluidic channels enabled the characterization of protein-refolding yield [15], protein aggregates polymorphism [21], and protein aggregation phenomena [24]. Droplet-based microfluidics offered dimensional scaling benefits that enable us to reduce more of the sample volume $[16-18,22,25,26]$, resulting in the detection of single primary protein nucleation and spatial propagation [22]. Moreover, microfluidic systems have been shown to have great promise as a tool for the characterization and separation of protein fibrils and aggregates by adapting single-molecule fluorescence [28], combined space and time data analysis [29], and electrophoresis [30,31]. Recent advances in microfluidic technologies, e.g., fast analysis, decreasing sample consumption, and automated flow control, enabled the increase in sensitivity and throughput. However, creating various incubation conditions by combining multiple concentration gradients of reagents remains challenging for the quantitative characterizations and kinetic studies of insulin fibrillation. Therefore, the development of a highly automated and integrated system is of great importance. Previously, microfluidic devices made by multilayer soft lithography [32,33] showed the potential of the parallelization of microreactors as a fast and automated diagnostic tool for biological and biotechnological applications, including protein crystallization [34,35], enzyme kinetics [36], DNA amplification [37-40], and cell culture [41,42]. However, the beneficial aspects of the large-scale integration of microfluidic reactors for high-throughput screening have not yet been exploited to address the challenge of the fast evaluation of protein fibrillation under various conditions with extremely small sample volumes.

Here, we developed a microfluidic protein aggregation device (microPAD) that enabled a series of protein incubations under various conditions. The device comprises 64 parallel incubation chambers to conduct 64 individual protein-folding reactions with varying concentrations of two factors. Using the microfluidic chip, we demonstrated nanoliter-scale bovine insulin aggregations, to evaluate the combined effect of concentrations of sodium chloride $(\mathrm{NaCl})$ and hydrochloric acid $(\mathrm{HCl})$ on the formation of insulin fibrils and fibrillar superstructures. Incubation of insulin, present in each reaction chamber in the same amount, was performed by using combinations of eight different concentrations of $\mathrm{NaCl}$ and $\mathrm{HCl}$, followed by monitoring of insulin fibril and spherulites formation, using a fluorescent marker (Thioflavin T). 


\section{Results and Discussion}

\subsection{Design and Fabrication of a MicroPAD}

The device consists of 64 incubation units. Each unit consists of a pushing line, a metering unit, and an incubation chamber (Figure 1A,B). Figure 1B shows the step-by-step operation of the device. The operation steps include (1) loading the reagents, (2) pushing the metered reagents into reaction chambers, and (3) mixing the reagents by using mixing valves located in the center of the chamber (Movie S1 in the Supplementary Materials). The metering unit comprises four loading sites: a dilution solution site (yellow color), a factor \#1 site (blue color), a factor \#2 site (red color), and a main factor site (green color). The samples were loaded by pressurizing them from the inlets while the central valves were closed and the side valves in the metering units were open (Figure 1B(a)). The metering units were designed to create stepwise gradients of two reagents, i.e., in the ratios of 1:1, 1:1.57, 1:2.13, 1:2.7, 1:3.27, 1:3.83, 1:4.4, and 1:4.97, for each reagent (Table 1). After the metering of the reagents, the central valves were closed, the side valves were opened, and the reagents were pushed into the incubation chambers (Figure $1 \mathrm{~B}(\mathrm{~b})$ ). Then, all valves were closed, and the reagents were mixed by the mixing valves (Figure $1 \mathrm{~B}(\mathrm{c})$ ). Figure $1 \mathrm{C}$ shows the design and operation of the mixing valves. The valves were designed to push up a certain volume at the center of the incubation chamber by actuation of the membrane between a fluidic channel and a control channel (Figure 1C(a)) [39,43,44]. The actuation height of the membrane is controlled by a pressure applied via the control channel, as was shown by simulation and testing (Figure S1 in the Supplementary Materials). The optimal pressure and operating frequency of the valve to mix reagents in the chamber were determined to be $0.2 \mathrm{bar}$ and $1.0 \mathrm{~Hz}$, respectively. Microscope images in Figure $1 \mathrm{C}(\mathrm{b})$ show de-actuation (top) and actuation (bottom) of four mixing valves. The operation of 8 mixing valves is shown in Movie S2 in the Supplementary Materials. The mixing efficiency was accessed by observing average brightness-value changes in incubation chamber areas during the mixing of the dye solutions (Figure S2 in the Supplementary Materials) [39]. The mixing of the loaded solutions in the incubation chambers was completed in less than $20 \mathrm{~s}(n=8)$.

\subsection{Calibration of the MicroPAD}

For characterization of the metering and mixing functionality of the device, concentration gradients of Rhodamine B isothiocyanate-Dextran (RD) were formed on a chip. Then, $1 \mathrm{~g} / \mathrm{L}$ of RD solution was introduced into dilution solution loading sites of the metering units, while factor \#1-, factor \#2-, and main factor loading sites were filled with Milli-Q water. After loading, the reagents were pushed into the incubation chambers and mixed for $3 \mathrm{~min}$ by operating the mixing valves. The final concentration of RD ranged from 73 to $543 \mathrm{mg} / \mathrm{L}$ (Figure 2A). In Figure 2B, the fluorescence image presents the concentration gradient of RD in 64 parallel incubation chambers, and Figure $2 \mathrm{C}$ shows the obtained fluorescence intensities of the chambers.

\subsection{The Effect of Insulin Concentration on Insulin Fibrillation}

The effect of the insulin concentration on insulin fibrillation was studied in 64 microfluidic incubation chambers. $\mathrm{HCl}$ solution containing $50 \mathrm{mM} \mathrm{HCl}$ and $20 \mu \mathrm{M}$ ThT; bovine insulin solution with $20 \mathrm{mg} / \mathrm{mL}$ bovine insulin; $50 \mathrm{mM} \mathrm{HCl}$ and $20 \mu \mathrm{M}$ ThT $\mathrm{HCl}$ solution containing $50 \mathrm{mM} \mathrm{HCl}$ and $20 \mu \mathrm{M}$ ThT; and $\mathrm{NaCl}$ solution containing $300 \mathrm{mM} \mathrm{NaCl} 50 \mathrm{mM} \mathrm{HCl}$ and $20 \mu \mathrm{M}$ ThT were introduced into dilution solution sites, factor \#1 sites, factor \#2 sites, and main factor loading site, respectively. As a result, eight sets of concentration gradients of bovine insulin were obtained, ranging from 6.77 to $1.36 \mathrm{mg} / \mathrm{mL}$, with a decrement of $0.77 \mathrm{mg} / \mathrm{mL}(50 \mathrm{mM} \mathrm{HCl}, 75 \mathrm{mM} \mathrm{NaCl}$, and $20 \mu \mathrm{M} \mathrm{ThT})$. 
A

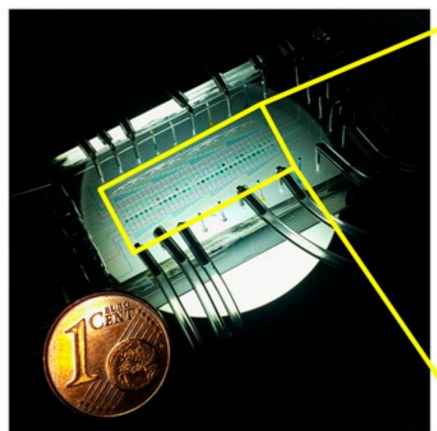

B

(a) Loading reagent

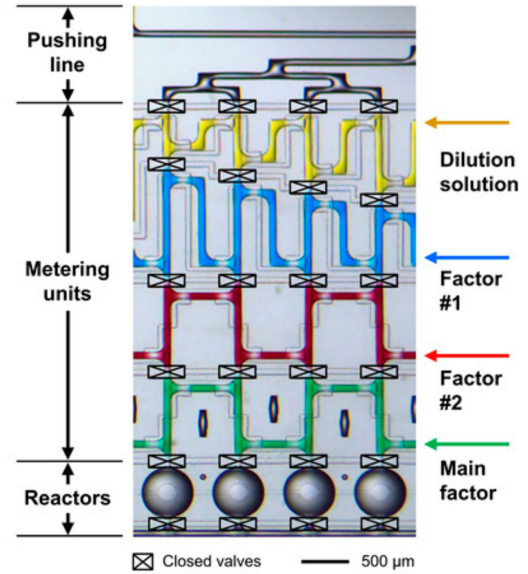

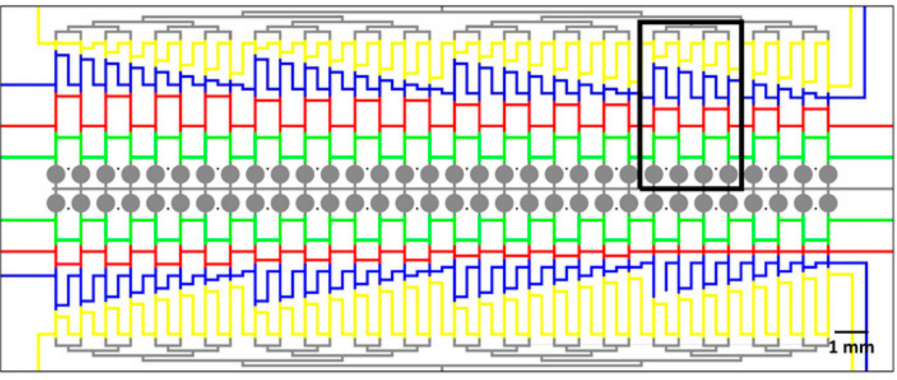

— Pushing reagents — Buffer - Factor\#1 — Factor \#2 - Main target

(b) Pushing in

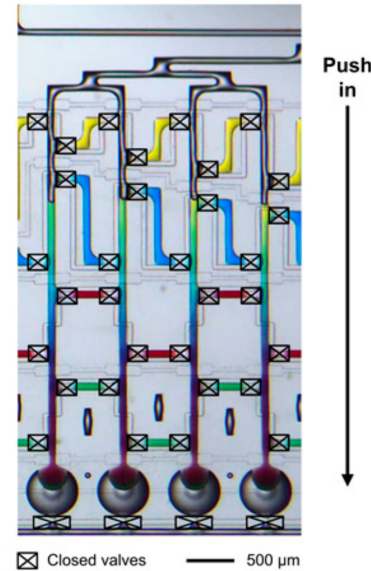

(c) Mixing reagents

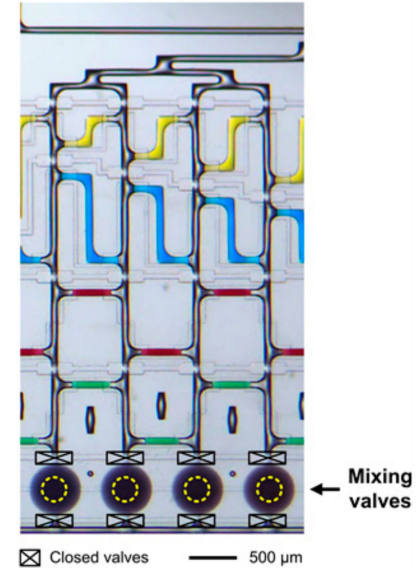

C

(a) Design of a mixing valve

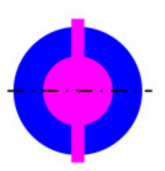

- Fluidic layer (PDMS) - Control layer
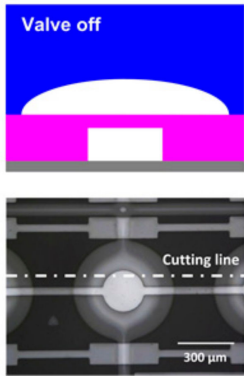
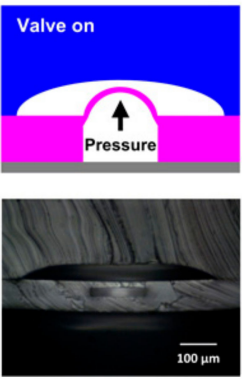

(b) Operation of mixing valves

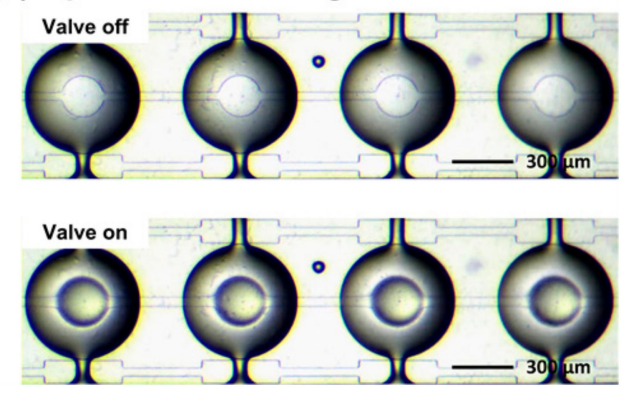

Figure 1. Design and operation of the microPAD. (A) Design of the device. (B) Operation of the device flows through (a) loading and metering, (b) pushing in, and (c) mixing. (C) (a) Design of a mixing valve and (b) operation of the mixing valves.

Figure $3 \mathrm{~A}$ shows one set of the measured fibrillation rates of bovine insulin as a function of insulin concentration. The insulin fibrillations progressed through a lag phase where ThT fluorescence was not detected and a growth phase by increasing the ThT intensities until a final steady state. Average lag times for insulin fibril formation $(n=8)$ are shown in Figure 3B. The fastest insulin aggregation was observed at the highest insulin concentration, and the rate of insulin fibrillation decreased according to the decrease in insulin concentration. Figure $3 \mathrm{C}$ shows the formation of insulin fibrillar structures in incubation chambers after a $90 \mathrm{~min}$ incubation. Longer incubation times of up to $180 \mathrm{~min}$ did not result in further changes in fibrillar structure formation. Fluorescent imaging of eight incubation chambers containing various concentrations of insulin showed differences in the density of the protein fibrillar structure. As opposed to spherulites, which consist of radially oriented amyloid fibrils from an empty core $[12,13,45]$, the fibrillar structures formed in the microfluidic chambers in this study exhibited a random orientation. The formation of dense fibril networks (or superstructures) was observed at high 
insulin concentrations by acquiring time-lapse fluorescence microscopy images of the incubation chambers. The initiation and growth of the superstructure were traced by acquiring time-series fluorescence microscope images of the incubation chambers.

Table 1. Compositions and combinations of the reagents in the 64 microfluidic incubation chambers.

\begin{tabular}{|c|c|c|c|c|c|c|c|}
\hline \multirow{2}{*}{$\begin{array}{l}\text { Reactor } \\
\text { Number }\end{array}$} & \multicolumn{3}{|c|}{ Final Concentration } & \multirow{2}{*}{$\begin{array}{l}\text { Reactor } \\
\text { Number }\end{array}$} & \multicolumn{3}{|c|}{ Final Concentration } \\
\hline & $\begin{array}{c}\text { Main Factor } \\
\text { ( } \mathrm{I}_{\mathbf{M}}: \text { Initial Conc.) }\end{array}$ & $\begin{array}{c}\text { Factor \#1 } \\
\left(\mathrm{I}_{\mathrm{F} 1}: \text { Initial Conc.) }\right.\end{array}$ & $\begin{array}{c}\text { Factor \#2 } \\
\left(\mathrm{I}_{\mathrm{F} 2}: \text { Initial Conc.) }\right.\end{array}$ & & $\begin{array}{c}\text { Main Factor } \\
\left(\mathrm{I}_{\mathbf{M}}: \text { Initial Conc.) }\right.\end{array}$ & $\begin{array}{c}\text { Factor \#1 } \\
\left(\mathrm{I}_{\mathrm{F} 1}: \text { Initial Conc.) }\right.\end{array}$ & $\begin{array}{c}\text { Factor \#2 } \\
\left(\mathrm{I}_{\mathrm{F} 2} \text { : Initial Conc.) }\right.\end{array}$ \\
\hline $1-1$ & $0.25 \mathrm{I}_{\mathrm{M}}$ & $0.34 \mathrm{I}_{\mathrm{F} 1}$ & $0.34 \mathrm{I}_{\mathrm{F} 2}$ & 5-1 & $0.25 \mathrm{I}_{\mathrm{M}}$ & $0.34 \mathrm{I}_{\mathrm{F} 1}$ & $0.18 \mathrm{I}_{\mathrm{F} 2}$ \\
\hline $1-2$ & $0.25 \mathrm{I}_{\mathrm{M}}$ & $0.30 \mathrm{I}_{\mathrm{F} 1}$ & $0.34 \mathrm{I}_{\mathrm{F} 2}$ & 5-2 & $0.25 \mathrm{I}_{\mathrm{M}}$ & $0.30 \mathrm{I}_{\mathrm{F} 1}$ & $0.18 \mathrm{I}_{\mathrm{F} 2}$ \\
\hline $1-3$ & $0.25 \mathrm{I}_{\mathrm{M}}$ & $0.26 \mathrm{I}_{\mathrm{F} 1}$ & $0.34 \mathrm{I}_{\mathrm{F} 2}$ & 5-3 & $0.25 \mathrm{I}_{\mathrm{M}}$ & $0.26 \mathrm{I}_{\mathrm{F} 1}$ & $0.18 \mathrm{I}_{\mathrm{F} 2}$ \\
\hline $1-4$ & $0.25 \mathrm{I}_{\mathrm{M}}$ & $0.22 \mathrm{I}_{\mathrm{F} 1}$ & $0.34 \mathrm{I}_{\mathrm{F} 2}$ & 5-4 & $0.25 \mathrm{I}_{\mathrm{M}}$ & $0.22 \mathrm{I}_{\mathrm{F} 1}$ & $0.18 \mathrm{I}_{\mathrm{F} 2}$ \\
\hline $1-5$ & $0.25 \mathrm{I}_{\mathrm{M}}$ & $0.18 \mathrm{I}_{\mathrm{F} 1}$ & $0.34 \mathrm{I}_{\mathrm{F} 2}$ & 5-5 & $0.25 \mathrm{I}_{\mathrm{M}}$ & $0.18 \mathrm{I}_{\mathrm{F} 1}$ & $0.18 \mathrm{I}_{\mathrm{F} 2}$ \\
\hline $1-6$ & $0.25 \mathrm{I}_{\mathrm{M}}$ & $0.15 \mathrm{I}_{\mathrm{F} 1}$ & $0.34 \mathrm{I}_{\mathrm{F} 2}$ & 5-6 & $0.25 \mathrm{I}_{\mathrm{M}}$ & $0.15 \mathrm{I}_{\mathrm{F} 1}$ & $0.18 \mathrm{I}_{\mathrm{F} 2}$ \\
\hline $1-7$ & $0.25 \mathrm{I}_{\mathrm{M}}$ & $0.11 \mathrm{I}_{\mathrm{F} 1}$ & $0.34 \mathrm{I}_{\mathrm{F} 2}$ & 5-7 & $0.25 \mathrm{I}_{\mathrm{M}}$ & $0.11 \mathrm{I}_{\mathrm{F} 1}$ & $0.18 \mathrm{I}_{\mathrm{F} 2}$ \\
\hline $1-8$ & $0.25 \mathrm{I}_{\mathrm{M}}$ & $0.07 \mathrm{I}_{\mathrm{F} 1}$ & $0.34 \mathrm{I}_{\mathrm{F} 2}$ & 5-8 & $0.25 \mathrm{I}_{\mathrm{M}}$ & $0.07 \mathrm{I}_{\mathrm{F} 1}$ & $0.18 \mathrm{I}_{\mathrm{F} 2}$ \\
\hline $2-1$ & $0.25 \mathrm{I}_{\mathrm{M}}$ & $0.34 \mathrm{I}_{\mathrm{F} 1}$ & $0.30 \mathrm{I}_{\mathrm{F} 2}$ & 6-1 & $0.25 \mathrm{I}_{\mathrm{M}}$ & $0.34 \mathrm{I}_{\mathrm{F} 1}$ & $0.15 \mathrm{I}_{\mathrm{F} 2}$ \\
\hline $2-2$ & $0.25 \mathrm{I}_{\mathrm{M}}$ & $0.30 \mathrm{I}_{\mathrm{F} 1}$ & $0.30 \mathrm{I}_{\mathrm{F} 2}$ & 6-2 & $0.25 \mathrm{I}_{\mathrm{M}}$ & $0.30 \mathrm{I}_{\mathrm{F} 1}$ & $0.15 \mathrm{I}_{\mathrm{F} 2}$ \\
\hline $2-3$ & $0.25 \mathrm{I}_{\mathrm{M}}$ & $0.26 \mathrm{I}_{\mathrm{F} 1}$ & $0.30 \mathrm{I}_{\mathrm{F} 2}$ & 6-3 & $0.25 \mathrm{I}_{\mathrm{M}}$ & $0.26 \mathrm{I}_{\mathrm{F} 1}$ & $0.15 \mathrm{I}_{\mathrm{F} 2}$ \\
\hline $2-4$ & $0.25 \mathrm{I}_{\mathrm{M}}$ & $0.22 \mathrm{I}_{\mathrm{F} 1}$ & $0.30 \mathrm{I}_{\mathrm{F} 2}$ & 6-4 & $0.25 \mathrm{I}_{\mathrm{M}}$ & $0.22 \mathrm{I}_{\mathrm{F} 1}$ & $0.15 \mathrm{I}_{\mathrm{F} 2}$ \\
\hline $2-5$ & $0.25 \mathrm{I}_{\mathrm{M}}$ & $0.18 \mathrm{I}_{\mathrm{F} 1}$ & $0.30 \mathrm{I}_{\mathrm{F} 2}$ & $6-5$ & $0.25 \mathrm{I}_{\mathrm{M}}$ & $0.18 \mathrm{I}_{\mathrm{F} 1}$ & $0.15 \mathrm{I}_{\mathrm{F} 2}$ \\
\hline $2-6$ & $0.25 \mathrm{I}_{\mathrm{M}}$ & $0.15 \mathrm{I}_{\mathrm{F} 1}$ & $0.30 \mathrm{I}_{\mathrm{F} 2}$ & 6-6 & $0.25 \mathrm{I}_{\mathrm{M}}$ & $0.15 \mathrm{I}_{\mathrm{F} 1}$ & $0.15 \mathrm{I}_{\mathrm{F} 2}$ \\
\hline $2-7$ & $0.25 \mathrm{I}_{\mathrm{M}}$ & $0.11 \mathrm{I}_{\mathrm{F} 1}$ & $0.30 \mathrm{I}_{\mathrm{F} 2}$ & $6-7$ & $0.25 \mathrm{I}_{\mathrm{M}}$ & $0.11 \mathrm{I}_{\mathrm{F} 1}$ & $0.15 \mathrm{I}_{\mathrm{F} 2}$ \\
\hline $2-8$ & $0.25 \mathrm{I}_{\mathrm{M}}$ & $0.07 \mathrm{I}_{\mathrm{F} 1}$ & $0.30 \mathrm{I}_{\mathrm{F} 2}$ & 6-8 & $0.25 \mathrm{I}_{\mathrm{M}}$ & $0.07 \mathrm{I}_{\mathrm{F} 1}$ & $0.15 \mathrm{I}_{\mathrm{F} 2}$ \\
\hline 3-1 & $0.25 \mathrm{I}_{\mathrm{M}}$ & $0.34 \mathrm{I}_{\mathrm{F} 1}$ & $0.26 \mathrm{I}_{\mathrm{F} 2}$ & $7-1$ & $0.25 \mathrm{I}_{\mathrm{M}}$ & $0.34 \mathrm{I}_{\mathrm{F} 1}$ & $0.11 \mathrm{I}_{\mathrm{F} 2}$ \\
\hline 3-2 & $0.25 \mathrm{I}_{\mathrm{M}}$ & $0.30 \mathrm{I}_{\mathrm{F} 1}$ & $0.26 \mathrm{I}_{\mathrm{F} 2}$ & $7-2$ & $0.25 \mathrm{I}_{\mathrm{M}}$ & $0.30 \mathrm{I}_{\mathrm{F} 1}$ & $0.11 \mathrm{I}_{\mathrm{F} 2}$ \\
\hline $3-3$ & $0.25 \mathrm{I}_{\mathrm{M}}$ & $0.26 \mathrm{I}_{\mathrm{F} 1}$ & $0.26 \mathrm{I}_{\mathrm{F} 2}$ & $7-3$ & $0.25 \mathrm{I}_{\mathrm{M}}$ & $0.26 \mathrm{I}_{\mathrm{F} 1}$ & $0.11 \mathrm{I}_{\mathrm{F} 2}$ \\
\hline $3-4$ & $0.25 \mathrm{I}_{\mathrm{M}}$ & $0.22 \mathrm{I}_{\mathrm{F} 1}$ & $0.26 \mathrm{I}_{\mathrm{F} 2}$ & $7-4$ & $0.25 \mathrm{I}_{\mathrm{M}}$ & $0.22 \mathrm{I}_{\mathrm{F} 1}$ & $0.11 \mathrm{I}_{\mathrm{F} 2}$ \\
\hline $3-5$ & $0.25 \mathrm{I}_{\mathrm{M}}$ & $0.18 \mathrm{I}_{\mathrm{F} 1}$ & $0.26 \mathrm{I}_{\mathrm{F} 2}$ & $7-5$ & $0.25 \mathrm{I}_{\mathrm{M}}$ & $0.18 \mathrm{I}_{\mathrm{F} 1}$ & $0.11 \mathrm{I}_{\mathrm{F} 2}$ \\
\hline 3-6 & $0.25 \mathrm{I}_{\mathrm{M}}$ & $0.15 \mathrm{I}_{\mathrm{F} 1}$ & $0.26 \mathrm{I}_{\mathrm{F} 2}$ & $7-6$ & $0.25 \mathrm{I}_{\mathrm{M}}$ & $0.15 \mathrm{I}_{\mathrm{F} 1}$ & $0.11 \mathrm{I}_{\mathrm{F} 2}$ \\
\hline $3-7$ & $0.25 \mathrm{I}_{\mathrm{M}}$ & $0.11 \mathrm{I}_{\mathrm{F} 1}$ & $0.26 \mathrm{I}_{\mathrm{F} 2}$ & $7-7$ & $0.25 \mathrm{I}_{\mathrm{M}}$ & $0.11 \mathrm{I}_{\mathrm{F} 1}$ & $0.11 \mathrm{I}_{\mathrm{F} 2}$ \\
\hline $3-8$ & $0.25 \mathrm{I}_{\mathrm{M}}$ & $0.07 \mathrm{I}_{\mathrm{F} 1}$ & $0.26 \mathrm{I}_{\mathrm{F} 2}$ & $7-8$ & $0.25 \mathrm{I}_{\mathrm{M}}$ & $0.07 \mathrm{I}_{\mathrm{F} 1}$ & $0.11 \mathrm{I}_{\mathrm{F} 2}$ \\
\hline $4-1$ & $0.25 \mathrm{I}_{\mathrm{M}}$ & $0.34 \mathrm{I}_{\mathrm{F} 1}$ & $0.22 \mathrm{I}_{\mathrm{F} 2}$ & 8-1 & $0.25 \mathrm{I}_{\mathrm{M}}$ & $0.34 \mathrm{I}_{\mathrm{F} 1}$ & $0.07 \mathrm{I}_{\mathrm{F} 2}$ \\
\hline $4-2$ & $0.25 \mathrm{I}_{\mathrm{M}}$ & $0.30 \mathrm{I}_{\mathrm{F} 1}$ & $0.22 \mathrm{I}_{\mathrm{F} 2}$ & $8-2$ & $0.25 \mathrm{I}_{\mathrm{M}}$ & $0.30 \mathrm{I}_{\mathrm{F} 1}$ & $0.07 \mathrm{I}_{\mathrm{F} 2}$ \\
\hline $4-3$ & $0.25 \mathrm{I}_{\mathrm{M}}$ & $0.26 \mathrm{I}_{\mathrm{F} 1}$ & $0.22 \mathrm{I}_{\mathrm{F} 2}$ & $8-3$ & $0.25 \mathrm{I}_{\mathrm{M}}$ & $0.26 \mathrm{I}_{\mathrm{F} 1}$ & $0.07 \mathrm{I}_{\mathrm{F} 2}$ \\
\hline $4-4$ & $0.25 \mathrm{I}_{\mathrm{M}}$ & $0.22 \mathrm{I}_{\mathrm{F} 1}$ & $0.22 \mathrm{I}_{\mathrm{F} 2}$ & 8-4 & $0.25 \mathrm{I}_{\mathrm{M}}$ & $0.22 \mathrm{I}_{\mathrm{F} 1}$ & $0.07 \mathrm{I}_{\mathrm{F} 2}$ \\
\hline $4-5$ & $0.25 \mathrm{I}_{\mathrm{M}}$ & $0.18 \mathrm{I}_{\mathrm{F} 1}$ & $0.22 \mathrm{I}_{\mathrm{F} 2}$ & $8-5$ & $0.25 \mathrm{I}_{\mathrm{M}}$ & $0.18 \mathrm{I}_{\mathrm{F} 1}$ & $0.07 \mathrm{I}_{\mathrm{F} 2}$ \\
\hline $4-6$ & $0.25 \mathrm{I}_{\mathrm{M}}$ & $0.15 \mathrm{I}_{\mathrm{F} 1}$ & $0.22 \mathrm{I}_{\mathrm{F} 2}$ & $8-6$ & $0.25 \mathrm{I}_{\mathrm{M}}$ & $0.15 \mathrm{I}_{\mathrm{F} 1}$ & $0.07 \mathrm{I}_{\mathrm{F} 2}$ \\
\hline $4-7$ & $0.25 \mathrm{I}_{\mathrm{M}}$ & $0.11 \mathrm{I}_{\mathrm{F} 1}$ & $0.22 \mathrm{I}_{\mathrm{F} 2}$ & 8-7 & $0.25 \mathrm{I}_{\mathrm{M}}$ & $0.11 \mathrm{I}_{\mathrm{F} 1}$ & $0.07 \mathrm{I}_{\mathrm{F} 2}$ \\
\hline $4-8$ & $0.25 \mathrm{I}_{\mathrm{M}}$ & $0.07 \mathrm{I}_{\mathrm{F} 1}$ & $0.22 \mathrm{I}_{\mathrm{F} 2}$ & 8-8 & $0.25 \mathrm{I}_{\mathrm{M}}$ & $0.07 \mathrm{I}_{\mathrm{F} 1}$ & $0.07 \mathrm{I}_{\mathrm{F} 2}$ \\
\hline
\end{tabular}

\subsection{The Effect of $\mathrm{NaCl}$ Concentration on Insulin Fibrillation}

A significant increase in the rate of insulin fibrillation as a result of the addition of $\mathrm{NaCl}$ has been reported in insulin incubation experiments due to the ion-protein interactions during the aggregation process $[5,7,46]$. To investigate the effect of the $\mathrm{NaCl}$ concentration on insulin fibrillation in the microPAD, a concentration gradient of $\mathrm{NaCl}$ was created while the concentration of bovine insulin was kept constant. The $\mathrm{NaCl}$ concentration was varied from 101.6 to $20.5 \mathrm{mM}$, with a decrement of $11.6 \mathrm{mM}$ $(5 \mathrm{mg} / \mathrm{mL}$ bovine insulin, $50 \mathrm{mM} \mathrm{HCl}$, and $20 \mu \mathrm{M}$ ThT) by loading $\mathrm{HCl}$ solution $(50 \mathrm{mM} \mathrm{HCl}$ and $20 \mu \mathrm{M}$ ThT), $\mathrm{NaCl}$ solution ( $300 \mathrm{mM} \mathrm{NaCl}, 50 \mathrm{mM} \mathrm{HCl}$ and $20 \mu \mathrm{M}$ ThT), $\mathrm{HCl}$ solution (50 mM HCl and $20 \mu \mathrm{M}$ ThT), and bovine insulin solution $(20 \mathrm{mg} / \mathrm{mL}$ bovine insulin, $40 \mathrm{mM} \mathrm{HCl}$ and $20 \mu \mathrm{M}$ ThT) into the dilution solution-, factor \#1-, factor \#2-, and main factor-loading site, respectively. The final concentrations of insulin, $\mathrm{HCl}$, and ThT were $5 \mathrm{mg} / \mathrm{mL}, 50 \mathrm{mM}$, and $20 \mu \mathrm{M}$, respectively, in all incubation chambers. Figure $4 \mathrm{~A}$ exhibits one set of the fibrillation rates of bovine insulin at different $\mathrm{NaCl}$ concentrations. An increase in the rate of bovine insulin fibrillation as a result of increased $\mathrm{NaCl}$ concentration was observed in eight incubation chambers. Figure $4 \mathrm{~B}$ shows average lag times for the formation of insulin fibrils $(n=8)$. Figure $4 \mathrm{C}$ shows the formation of insulin fibrillar structures at various concentrations of $\mathrm{NaCl}$ after a 90 min incubation. The highly crowded superstructures were observed in the case of incubations at high $\mathrm{NaCl}$ concentrations, and a decrease in $\mathrm{NaCl}$ concentration led to a decrease in the density of fibril superstructures. At the concentrations of $\mathrm{NaCl}$ below $43.6 \mathrm{mM}$, spherulites formed rather than random fibrillar (super)structures. 
A

\begin{tabular}{|c|c|c|c|c|c|c|c|c|c|c|c|c|c|c|c|}
\hline $\begin{array}{l}\text { Reactor } \\
\text { number }\end{array}$ & $\begin{array}{c}\text { RD } \\
{[\mathrm{mg} / \mathrm{L}]}\end{array}$ & $\begin{array}{l}\text { Reactor } \\
\text { number }\end{array}$ & $\begin{array}{c}\text { RD } \\
{[\mathrm{mg} / \mathrm{L}]}\end{array}$ & $\begin{array}{l}\text { Reactor } \\
\text { number }\end{array}$ & $\begin{array}{c}\text { RD } \\
{[\mathrm{mg} / \mathrm{L}]}\end{array}$ & $\begin{array}{l}\text { Reactor } \\
\text { number }\end{array}$ & $\begin{array}{c}\text { RD } \\
{[\mathrm{mg} / \mathrm{L}]}\end{array}$ & $\begin{array}{l}\text { Reactor } \\
\text { number }\end{array}$ & $\begin{array}{c}\mathrm{RD} \\
{[\mathrm{mg} / \mathrm{L}]}\end{array}$ & $\begin{array}{l}\text { Reactor } \\
\text { number }\end{array}$ & $\begin{array}{c}\mathrm{RD} \\
{[\mathrm{mg} / \mathrm{L}]}\end{array}$ & $\begin{array}{l}\text { Reactor } \\
\text { number }\end{array}$ & $\begin{array}{c}\text { RD } \\
{[\mathrm{mg} / \mathrm{L}]}\end{array}$ & $\begin{array}{l}\text { Reactor } \\
\text { number }\end{array}$ & $\begin{array}{c}\mathrm{RD} \\
{[\mathrm{mg} / \mathrm{L}]}\end{array}$ \\
\hline $1-1$ & 73 & $2-1$ & 111 & $3-1$ & 150 & 4- 1 & 189 & $5-1$ & 227 & $6-1$ & 266 & $7-1$ & 305 & $8-1$ & 343 \\
\hline 1-2 & 111 & $2-2$ & 150 & 3-2 & 189 & 4- 2 & 227 & $5-2$ & 266 & $6-2$ & 305 & 7-2 & 343 & $8-2$ & 382 \\
\hline $1-3$ & 150 & $2-3$ & 189 & $3-3$ & 227 & $4-3$ & 266 & $5-3$ & 305 & $6-3$ & 343 & $7-3$ & 382 & $8-3$ & 420 \\
\hline $1-4$ & 189 & 2- 4 & 227 & 3- 4 & 266 & $4-4$ & 305 & $5-4$ & 343 & $6-4$ & 382 & $7-4$ & 420 & 8- 4 & 459 \\
\hline $1-5$ & 227 & $2-5$ & 266 & 3- 5 & 305 & $4-5$ & 343 & $5-5$ & 382 & $6-5$ & 420 & $7-5$ & 459 & 8- 5 & 498 \\
\hline $1-6$ & 266 & $2-6$ & 305 & $3-6$ & 343 & $4-6$ & 382 & $5-6$ & 420 & $6-6$ & 459 & $7-6$ & 498 & $8-6$ & 536 \\
\hline $1-7$ & 305 & $2-7$ & 343 & $3-7$ & 382 & 4-7 & 420 & $5-7$ & 459 & $6-7$ & 498 & $7-7$ & 536 & 8-7 & 575 \\
\hline $1-8$ & 343 & $2-8$ & 382 & 3- 8 & 420 & $4-8$ & 459 & $5-8$ & 498 & $6-8$ & 536 & $7-8$ & 575 & 8- 8 & 614 \\
\hline
\end{tabular}

B

$\begin{array}{lllllllllllllllllllllllllllllllllll}1-1 & 1-2 & 1-3 & 1-4 & 1-5 & 1-6 & 1-7 & 1-8 & 2-1 & 2-2 & 2-3 & 2-4 & 2-5 & 2-6 & 2-7 & 2-8 & 3-1 & 3-2 & 3-3 & 3-4 & 3-5 & 3-6 & 3-7 & 3-8 & 4-1 & 4-2 & 4-3 & 4-4 & 4-5 & 4-6 & 4-7 & 4-8\end{array}$

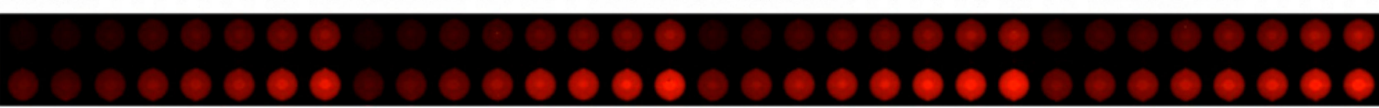

5-1 5-2 5-3 5-4 5-5 5-6 5-7 5-8 6-1 6-2 6-3 6-4 6-5 6-6 6-7 6-8 7-1 7-2 7-3 7-4 7-5 7-6 7-7 7-8 8-1 8-2 8-3 8-4 8-5 8-6 8-7 8-8

C

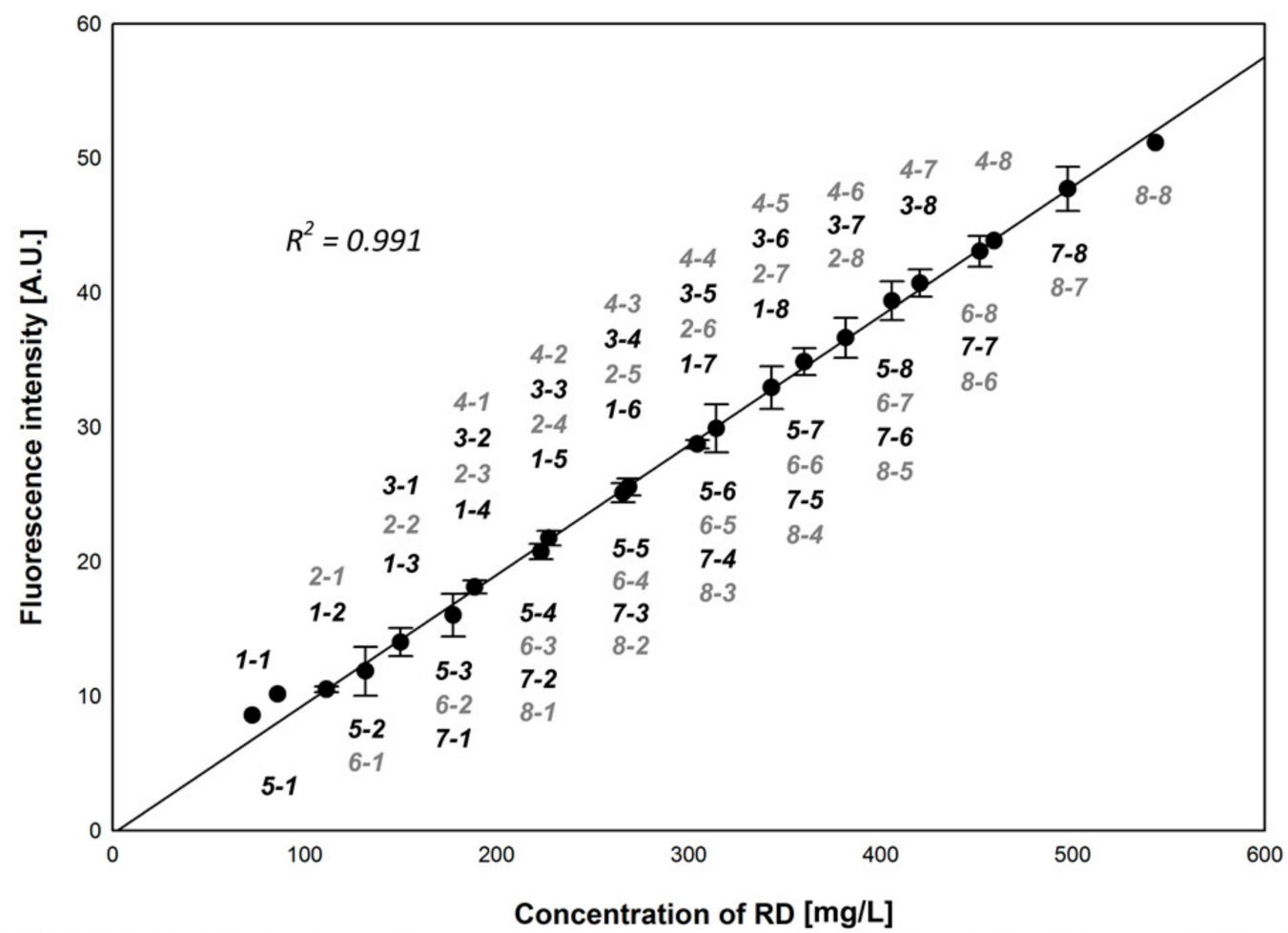

Figure 2. On-chip concentration gradient of RD. (A) Calculated final concentrations of RD in the 64 incubation chambers. (B) An acquired fluorescence image of the 64 parallel incubation chambers. (C) The relationship between the calculated concentrations of RD and the obtained RD fluorescent intensities in the chambers.

It is worth mentioning that the insulin fibrillation rate in our microfluidic device was higher than the fibrillation rate observed in conventional incubation $[5,7,9]$ as well as in other microfluidic platforms [22]. The rapid on-chip insulin fibrillation was suggested to be mainly affected by the small reactor volume [22], but also the hydrophobicity of polydimethylsiloxane (PDMS) surface of the device expectedly increases the insulin fibrillation rate [1,7]. With the device developed here, we succeeded in reproducing eight sets of conventional incubation experiments in a single experiment. The two on-chip incubations, one with varying concentrations of insulin at a constant concentration of $\mathrm{NaCl}$ and the other with different concentrations of $\mathrm{NaCl}$ at a fixed concentration of insulin, shows explicit agreement on 
the effect of the two parameters on insulin fibrillation. Hence even the effect of an unknown parameter on insulin fibrillation can be evaluated by applying a new parameter with unknown effect, with one of the well-defined parameters for on-chip insulin incubations.

A

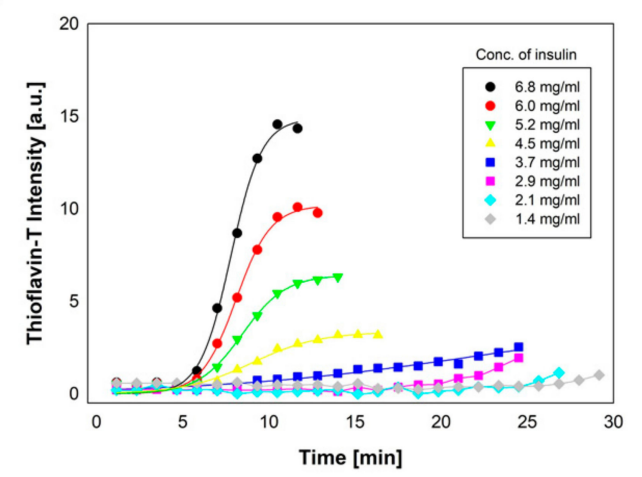

B

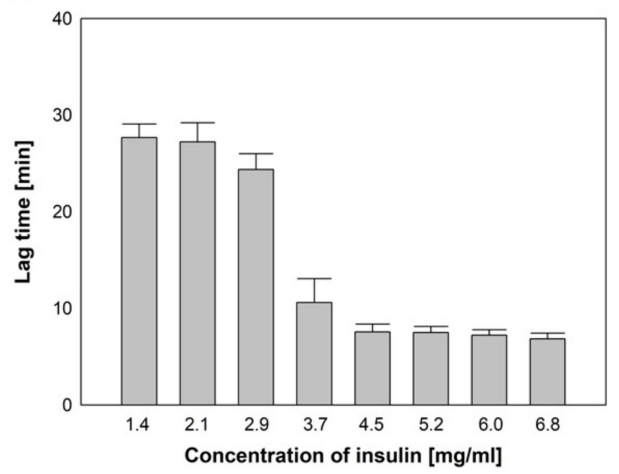

C

Superstructures of Insulin

( various concentrations of bovine insulin, $50 \mathrm{mM} \mathrm{HCl}, 75 \mathrm{mM} \mathrm{NaCl}$, and $20 \mu \mathrm{M} \mathrm{ThT}$ at $60^{\circ} \mathrm{C}$ )

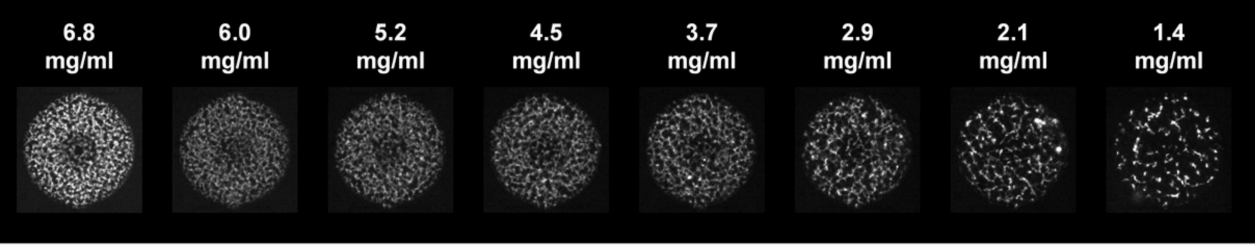

Figure 3. The effect of insulin concentration on insulin fibrillation. (A) The fluorescent intensity changes of ThT as a marker of insulin fibrillation. (B) Average lag times for insulin fibril formation $(n=8)$ and $(\mathbf{C})$ the formation of insulin superstructures at various concentrations of insulin $(50 \mathrm{mM} \mathrm{HCl}$, $75 \mathrm{mM} \mathrm{NaCl}$, and $20 \mu \mathrm{M}$ ThT).

A

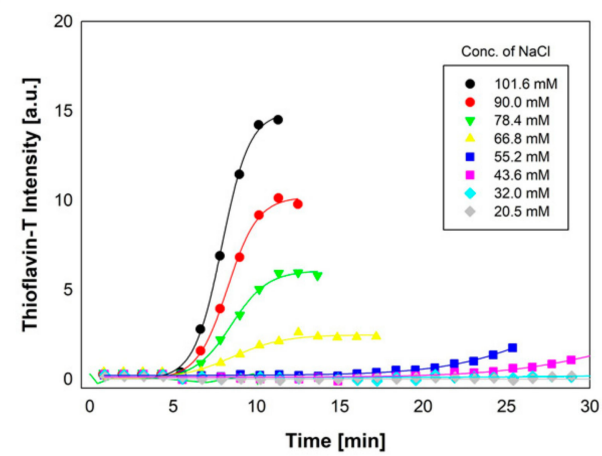

B

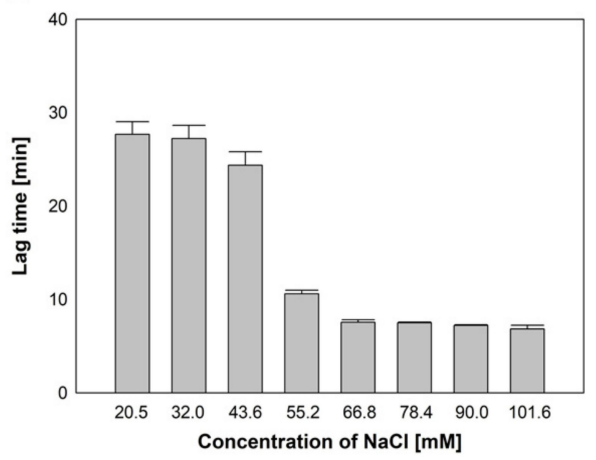

C

Superstructures of Insulin

( various concentrations of $\mathrm{NaCl}, 5 \mathrm{mg} / \mathrm{ml}$ bovine insulin, $50 \mathrm{mM} \mathrm{HCl}$, and $20 \mu \mathrm{M} \mathrm{ThT}$ at $60{ }^{\circ} \mathrm{C}$ )

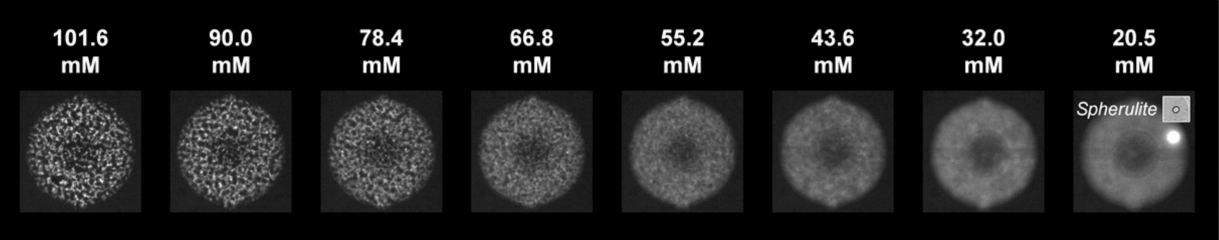

Figure 4. The effect of $\mathrm{NaCl}$ concentration on insulin fibrillation. (A) The rates of insulin fibrillation and (B) average lag times for insulin fibril formation $(n=8)$ at various $\mathrm{NaCl}$ concentrations $(5 \mathrm{mg} / \mathrm{mL}$ bovine insulin, $50 \mathrm{mM} \mathrm{HCl}$, and $20 \mu \mathrm{M} \mathrm{ThT}$ ). (C) Fluorescent images of insulin superstructures formed in microfluidic incubation chambers. The inset shows the bright-field microscope image of a spherulite. 


\subsection{The Combined Effects of Different Concentrations of $\mathrm{NaCl}$ and $\mathrm{HCl}$ on Insulin Fibrillation}

To evaluate the combined effects of $\mathrm{NaCl}$ and $\mathrm{HCl}$ concentrations on insulin fibrillation, dual concentration gradients of $\mathrm{NaCl}$ and $\mathrm{HCl}$ were formed in the microPAD. Milli-Q water, $\mathrm{HCl}$ solution ( $50 \mathrm{mM} \mathrm{HCl}$ and $20 \mu \mathrm{M}$ ThT), $\mathrm{NaCl}$ solution ( $300 \mathrm{mM} \mathrm{NaCl}$ and $20 \mu \mathrm{M}$ ThT), and bovine insulin solution ( $20 \mathrm{mg} / \mathrm{mL}$ bovine insulin, $50 \mathrm{mM} \mathrm{HCl}$, and $20 \mu \mathrm{M}$ ThT) were introduced into the dilution solution-, factor \#1-, factor \#2-, and main factor-loading site, respectively. At a constant concentration of bovine insulin of $5 \mathrm{mg} / \mathrm{mL}$, the concentration of $\mathrm{NaCl}$ ranged from 101.6 to $20.5 \mathrm{mM}$, with a decrement of $11.6 \mathrm{mM}$, and the concentration of $\mathrm{HCl}$ varied from 16.9 to $3.4 \mathrm{mM}$, with a decrement of $1.9 \mathrm{mM}$. Figure 5 shows $\mathrm{HCl}$ and $\mathrm{NaCl}$ concentrations (Figure $5 \mathrm{~A}$ ), calculated $\mathrm{pH}$ and ionic strength values (Figure 5B), and measured lag times for the formation of insulin fibrils (Figure 5C) in 64 chambers. The lag times decreased with an increase in the $\mathrm{NaCl}$ concentration, at a constant $\mathrm{HCl}$ concentration and with an increase in the $\mathrm{HCl}$ concentration at a constant $\mathrm{NaCl}$ concentration. At $\mathrm{NaCl}$ concentrations of 101.6 and $90.0 \mathrm{mM}$, increased concentrations of $\mathrm{HCl}$ led to shorter lag times; however, a definite trend of lag time decreasing with increasing $\mathrm{HCl}$ concentration was observed in the concentration ranges of $\mathrm{NaCl}$ lower than $78.4 \mathrm{mM}$. The on-chip fibrillation experiments further showed that low $\mathrm{pH}$ and high ionic strength decreased the lag time of the insulin fibril formation, and that ionic strength is a dominant factor for insulin fibrillation when the ionic strength is higher than $0.09 \mathrm{~mol} / \mathrm{L}$.

A

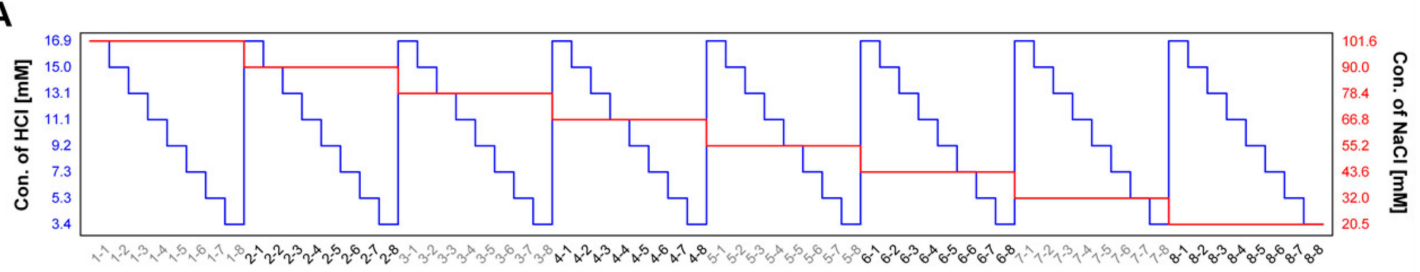

B

Reactor number

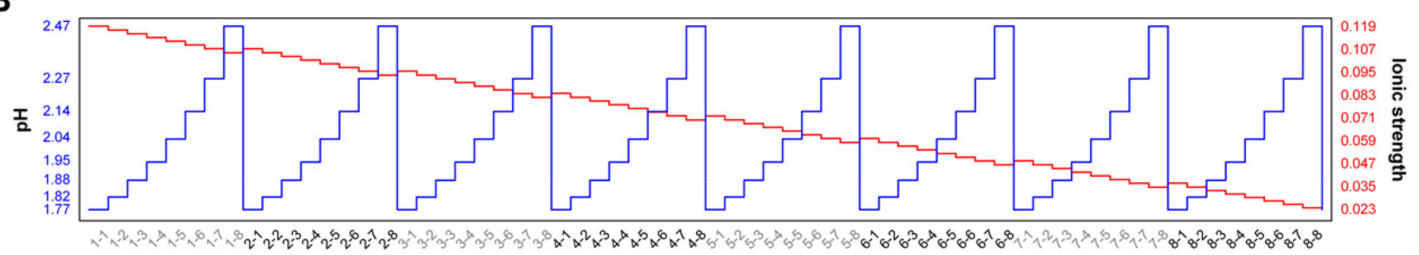

C

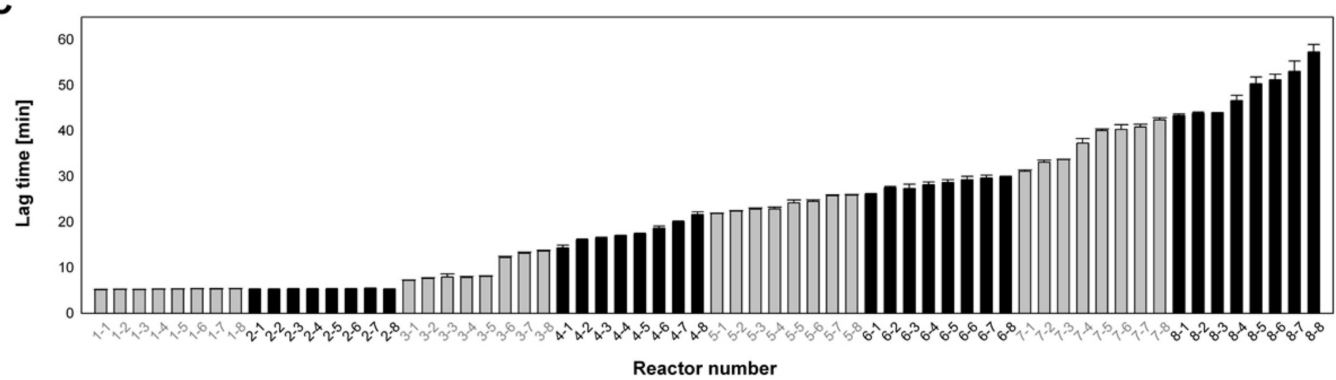

Figure 5. The combined effect of concentrations of $\mathrm{NaCl}$ and $\mathrm{HCl}$ on insulin fibrillation. (A) Concentrations of $\mathrm{HCl}$ (blue) and $\mathrm{NaCl}$ (red), (B) calculated $\mathrm{pH}$ (blue) and ionic strength (red) values, and $(\mathrm{C})$ measured lag times for the formation of insulin fibril $(n=3)$ in the 64 incubation chambers.

Figure 6 shows the formation of fibril structures in 64 parallel chambers with various combinations of $\mathrm{NaCl}$ and $\mathrm{HCl}$ concentrations after a 90-min incubation. The red dashed circles indicate the formation of superstructures of bovine insulin and yellow dashed circles exhibit the formation of insulin fibrils. The intensity strength of the colors indicates the density of the formation of insulin fibrillar structures. At high concentrations of $\mathrm{NaCl}$ and $\mathrm{HCl}$, relatively thick superstructures of insulin were observed, and the process of insulin fibrillation seems to be finalized. At the intermediate concentrations of $\mathrm{NaCl}$ and $\mathrm{HCl}$, the formation of hairy but crowded fibrillar networks was observed. The formation of 
spherulites was found at low concentrations of $\mathrm{NaCl}$ and $\mathrm{HCl}$, and the fibril structure formation was likely still ongoing. The spherulites were formed near the intermediate concentration of $\mathrm{NaCl}$ and $\mathrm{HCl}$ and were rarely observed at high concentrations of $\mathrm{NaCl}$ and $\mathrm{HCl}$.

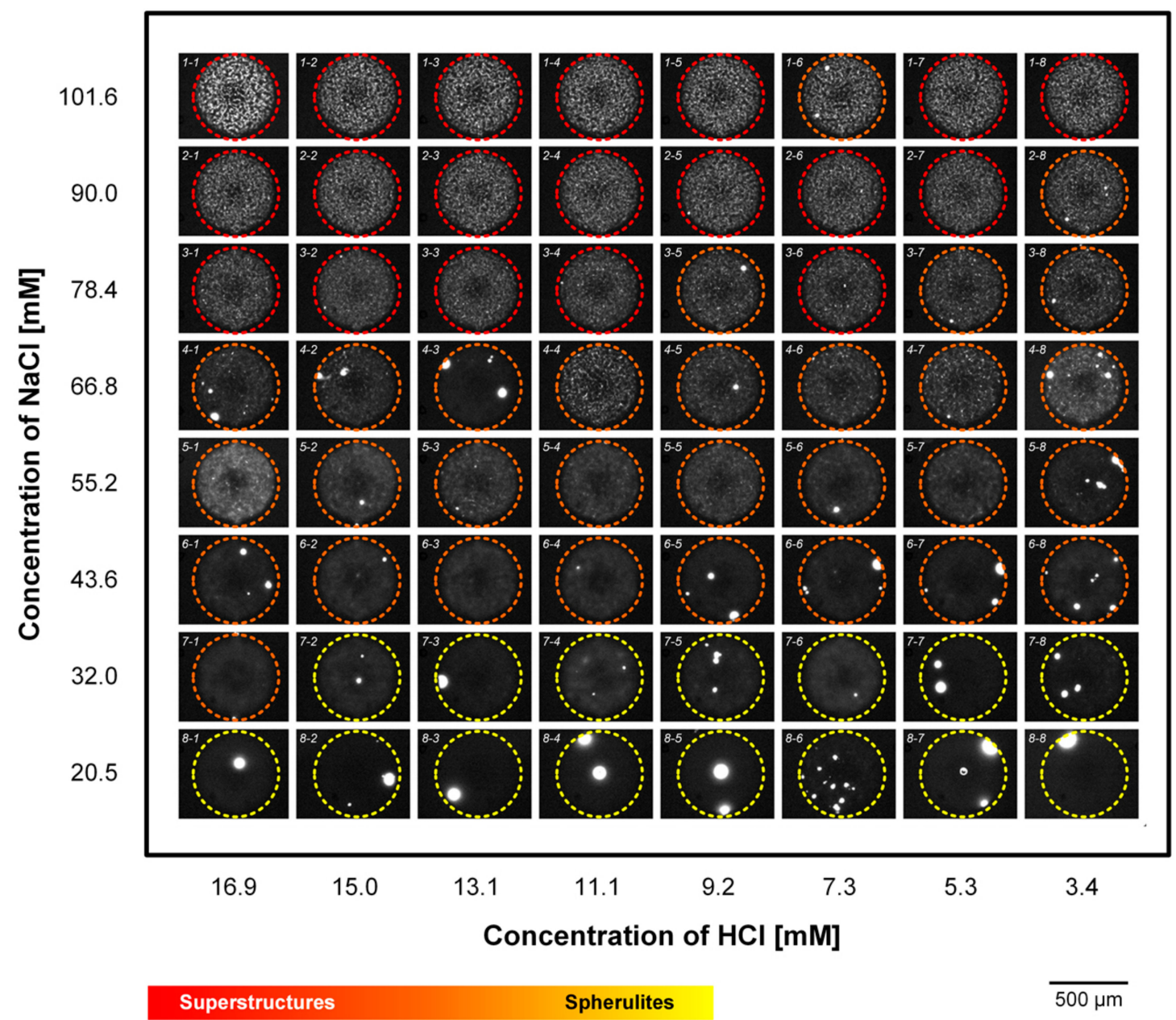

Figure 6. The combined effect of concentrations of $\mathrm{NaCl}$ and $\mathrm{HCl}$ on insulin fibrillar structure formation after $90 \mathrm{~min}$ of incubation.

\section{Materials and Methods}

\subsection{Materials}

Insulin from bovine pancreas was obtained from Sigma-Aldrich (Zwijndrecht, The Netherlands) and dissolved at $20 \mathrm{mg} / \mathrm{mL}$ protein concentration in deionized water from Milli-Q filtration system (Millipore Co.), along with $50 \mathrm{mM} \mathrm{HCl}$ (Sigma-Aldrich, Zwijndrecht, The Netherlands) and $20 \mu \mathrm{M}$ ThT (Sigma-Aldrich, Zwijndrecht, The Netherlands). Dilution buffer solution (50 mM HCl and $20 \mu \mathrm{M}$ ThT), $\mathrm{NaCl}$ solution ( $300 \mathrm{mM} \mathrm{NaCl}, 50 \mathrm{mM} \mathrm{HCl}$, and $20 \mu \mathrm{M}$ ThT), and neutral buffer solution $(20 \mu \mathrm{M}$ ThT, pH 7.0) were prepared with Milli-Q water. $\mathrm{NaCl}$ solution was filtered with a $0.2 \mu \mathrm{m}$ syringe filter (Whatman PLC, Sigma-Aldrich, Zwijndrecht, The Netherlands), to remove any residual solids.

\subsection{Chip Fabrication}

The microPAD consists of a PDMS fluidic layer and a PDMS control layer, which were fabricated by using the previously reported multilayer soft lithography technique [32,33]. Details of the fabrication process are described in Protocol S1 in the Supplementary Materials. 


\subsection{Simulation of the Actuation of Mixing Valves}

Characterization of the mixing valves was processed based on stationary finite element simulations, using COMSOL MultiPhysics 5.1 (COMSOL MultiPhysics, Stockholm, Sweden) with the physics packages "Solid mechanics (solid)" and "Moving Mesh (ale)". The model was built with the standard CAD kernel of COMSOL and is a simplification of the real device, i.e., it does not include the microchannels. The incubation chamber was considered half of an ellipsoid and the pressure chamber a cylinder. All domains were made of PDMS (density: $970 \mathrm{~kg} \mathrm{~m}^{-3}$, Young's modulus: $0.7 \mathrm{GPa}$, Poisson's ratio: 0.49), and the pressure was applied via a boundary load. The COMSOL model for the simulation of mixing valve actuation is provided in the Supplementary Materials.

\subsection{Temperature Control}

An indium tin oxide (ITO) heater and a temperature controller were purchased from Cell MicroControls (Norfolk, VA, USA). The controller was calibrated to adjust and control the temperature in the fluidic channels of the device. Details about the temperature control setup are provided in Figure S3 in the Supplementary Materials.

\subsection{PDMS Membrane Valve Operation}

The fluid flow in the microfluidic devices was controlled with a pneumatic control system. Microvalves were operated by applying compressed nitrogen gas into control channels. The pneumatic control system was automated by combining precision pressure regulators, 3/2-way solenoid valves, and EasyPort USB digital I/O controller (all from Festo, Delft, The Netherlands). The pneumatic system was controlled by a custom-built LabVIEW program (National Instruments Co., Austin, USA).

\subsection{Insulin Aggregation on a Chip}

After loading reagents into incubation chambers, we mixed them by operating the mixing valves $(0.1 \mathrm{~Hz}$ for $3 \mathrm{~min})$, and the device was heated to $60^{\circ} \mathrm{C}$ by controlling the ITO heater. Then, the monitoring of the aggregation processes in 64 chambers by ThT based fluorescence was initiated. ThT fluorescence is associated with the binding of the marker to protein fibrils [47,48].

\subsection{Data Processing}

An inverted fluorescent microscope (Olympus IX73, Olympus, Leiderdorp, The Netherlands) was used that was equipped with an automatic XY-stage (99S000, Ludl Electronic Products Ltd., NY, USA) and a digital camera (ORCA-ER, Hamamatsu Photonics Deutschland GmbH, Herrsching, Germany), for the acquisition of images, in order to monitor the microfluidic reactors. The stage and camera were interconnected by a custom-built LabVIEW program (National Instruments Co., Austin, USA), to automatically acquire images in predefined regions of interest with programmed time intervals. The fluorescent signal from ThT-bound insulin fibrils was acquired by a filter cube (excitation: $436 \mathrm{~nm}$; emission: $480 \mathrm{~nm}$, Chroma Technology Corp., Vermont, USA). The acquired images were processed and analyzed by the time-series analyzer of Image J software (http://rsb.info.nih.gov/ij/). For the kinetic study of fibril formation, the obtained ThT fluorescence intensities were plotted as a function of time and fitted by a sigmoidal curve by using SigmaPlot (Systat Software Inc., San Jose, USA). The lag times for the formation of fibrils under various incubation conditions were determined by Equation S1 in the Supplementary Materials.

\section{Conclusions}

In this work, we established a high-throughput method to study protein aggregation, using 64 parallel incubation chambers on a single microfluidic chip. We presented the creation of nonlinear concentration gradients of $\mathrm{HCl}$ and $\mathrm{NaCl}$ and investigated their influences on insulin aggregation. The kinetics of fibril formation and the morphology of fibrillar structures under different conditions 
were investigated. The microPAD device developed here may be a useful tool for rapid evaluation of amyloid growth and the formation of fibrillar structures associated with many misfolding-based diseases, such as Alzheimer's and Parkinson's disease.

Supplementary Materials: The following are available online. Figure S1: Actuation of a mixing valve at various applied pressures. Figure S2: Mixing efficiency test. Protocol S1: Fabrication process of microfluidic devices. Figure S3: Temperature control setup. Equation S1: Kinetics of insulin fibril formation. Figure S4: Microfluidic device design for the optimization of operations. Movie S1: Device operation. Movie S2: Mixing valve operation, and COMSOL model file-the simulation of mixing valve actuation.

Author Contributions: H.S.R., A.T.H., M.O., and H.G. designed the experiments; H.S.R. designed and fabricated the microPAD; H.S.R., H.-W.V., and C.B. set up, performed, and analyzed the experiments; H.S.R., H.-W.V., P.H., and H.G. wrote the manuscript. All authors edited and reviewed the manuscript. All authors have read and agreed to the published version of the manuscript.

Funding: This research was financially supported by the BE-Basic foundation (funded by the Ministry of Economic Affairs of The Netherlands, grant number: FES0905), a public-private partnership of knowledge institutes, industry, and academia, under the project no. FS2.003.

Acknowledgments: We want to thank our industrial partners in the BE-Basic foundation for valuable input during the progress meetings. P.H. gratefully acknowledges the Gravitation Program "Materials Driven Regeneration", funded by The Netherlands Organization for Scientific Research (024.003.013), Innovational Research Incentives Scheme Vidi (\# 15604) of the NWO, and the Dutch Province of Limburg (LINK Project).

Conflicts of Interest: The authors declare no conflict of interest.

\section{References}

1. Selkoe, D.J. Folding proteins in fatal ways. Nature 2003, 426, 900-904. [CrossRef] [PubMed]

2. Estes, D.J.; Lopez, S.R.; Fuller, A.O.; Mayer, M. Triggering and visualizing the aggregation and fusion of lipid membranes in microfluidic chambers. Biophys. J. 2006, 91, 233-243. [CrossRef] [PubMed]

3. Reaven, G.M. Role of insulin resistance in human disease. Diabetes 1988, 37, 1595-1607. [CrossRef]

4. Uversky, V.N. Natively unfolded proteins: A point where biology waits for physics. Protein Sci. 2002, 11, 739-756. [CrossRef] [PubMed]

5. Nielsen, L.; Frokjaer, S.; Brange, J.; Uversky, V.N.; Fink, A.L. Probing the mechanism of insulin fibril formation with insulin mutants. Biochemistry 2001, 40, 8397-8409. [CrossRef]

6. Hua, Q.X.; Weiss, M.A. Mechanism of insulin fibrillation: The structure of insulin under amyloidogenic conditions resembles a protein-folding intermediate. J. Biol. Chem. 2004, 279, 21449-21460. [CrossRef]

7. Brange, J.; Andersen, L.; Laursen, E.D.; Meyn, G.; Rasmussen, E. Toward understanding insulin fibrillation. J. Pharm. Sci. 1997, 86, 517-525. [CrossRef]

8. Tiiman, A.; Noormägi, A.; Friedemann, M.; Krishtal, J.; Palumaa, P.; Tõugu, V. Effect of agitation on the peptide fibrillization: Alzheimer's amyloid- $\beta$ peptide 1-42 but not amylin and insulin fibrils can grow under quiescent conditions. J. Pept. Sci. 2013, 19, 386-391. [CrossRef]

9. Nielsen, L.; Khurana, R.; Coats, A.; Frokjaer, S.; Brange, J.; Vyas, S.; Uversky, V.N.; Fink, A.L. Effect of environmental factors on the kinetics of insulin fibril formation: Elucidation of the molecular mechanism. Biochemistry 2001, 40, 6036-6046. [CrossRef]

10. Wang, W. Protein aggregation and its inhibition in biopharmaceutics. Int. J. Pharm. 2005, 289, 1-30. [CrossRef]

11. Brange, J.; Langkjoer, L. Insulin structure and stability. Pharm. Biotechnol. 1993, 5, 315-350. [PubMed]

12. Krebs, M.R.H.; Bromley, E.H.C.; Rogers, S.S.; Donald, A.M. The mechanism of amyloid spherulite formation by bovine insulin. Biophys. J. 2005, 88, 2013-2021. [CrossRef] [PubMed]

13. Krebs, M.R.H.; MacPhee, C.E.; Miller, A.F.; Dunlop, I.E.; Dobson, C.M.; Donald, A.M. The formation of spherulites by amyloid fibrils of bovine insulin. Proc. Natl. Acad. Sci. USA 2004, 101, 14420-14424. [CrossRef] [PubMed]

14. Pryor, E.; Kotarek, J.A.; Moss, M.A.; Hestekin, C.N. Monitoring insulin aggregation via capillary electrophoresis. Int. J. Mol. Sci. 2011, 12, 9369-9388. [CrossRef]

15. Yamaguchi, H.; Miyazaki, M.; Briones-Nagata, M.P.; Maeda, H. Refolding of difficult-to-fold proteins by a gradual decrease of denaturant using microfluidic chips. J. Biochem. 2010, 147, 895-903. [CrossRef]

16. Levin, A.; Mason, T.O.; Knowles, T.P.J.; Shimanovich, U. Self-assembled Protein Fibril-metal Oxide Nanocomposites. Isr. J. Chem. 2017, 57, 724-728. [CrossRef] 
17. Courtney, M.; Chen, X.; Chan, S.; Mohamed, T.; Rao, P.P.N.; Ren, C.L. Droplet Microfluidic System with On-Demand Trapping and Releasing of Droplet for Drug Screening Applications. Anal. Chem. 2017, 89, 910-915. [CrossRef]

18. Zhou, X.M.; Shimanovich, U.; Herling, T.W.; Wu, S.; Dobson, C.M.; Knowles, T.P.J.; Perrett, S. Enzymatically Active Microgels from Self-Assembling Protein Nanofibrils for Microflow Chemistry. ACS Nano 2015, 9, 5772-5781. [CrossRef] [PubMed]

19. Herling, T.W.; Garcia, G.A.; Michaels, T.C.T.; Grentz, W.; Dean, J.; Shimanovich, U.; Gang, H.; Müller, T.; Kav, B.; Terentjev, E.M.; et al. Force generation by the growth of amyloid aggregates. Proc. Natl. Acad. Sci. USA 2015, 112, 9524-9529. [CrossRef] [PubMed]

20. Lee, J.S.; Ryu, J.; Park, C.B. High-throughput analysis of alzheimer's $\beta$-amyloid aggregation using a microfluidic self-assembly of monomersf. Anal. Chem. 2009, 81, 2751-2759. [CrossRef]

21. Foderá, V.; Pagliara, S.; Otto, O.; Keyser, U.F.; Donald, A.M. Microfluidics reveals a flow-induced large-scale polymorphism of protein aggregates. J. Phys. Chem. Lett. 2012, 3, 2803-2807. [CrossRef]

22. Knowles, T.P.J.; White, D.A.; Abate, A.R.; Agresti, J.J.; Cohen, S.I.A.; Sperling, R.A.; De Genst, E.J.; Dobson, C.M.; Weitz, D.A. Observation of spatial propagation of amyloid assembly from single nuclei. Proc. Natl. Acad. Sci. USA 2011, 108, 14746-14751. [CrossRef] [PubMed]

23. Lee, J.S.; Um, E.; Park, J.K.; Park, C.B. Microfluidic self-assembly of insulin monomers into amyloid fibrils on a solid surface. Langmuir 2008, 24, 7068-7071. [CrossRef] [PubMed]

24. Saar, K.L.; Yates, E.V.; Müller, T.; Saunier, S.; Dobson, C.M.; Knowles, T.P.J. Automated Ex Situ Assays of Amyloid Formation on a Microfluidic Platform. Biophys. J. 2016, 110, 555-560. [CrossRef]

25. Park, M.C.; Kim, M.; Lim, G.T.; Kang, S.M.; An, S.S.A.; Kim, T.S.; Kang, J.Y. Droplet-based magnetic bead immunoassay using microchannel-connected multiwell plates ( $\mu$ CHAMPs) for the detection of amyloid beta oligomers. Lab. Chip 2016, 16, 2245-2253. [CrossRef]

26. Meier, M.; Kennedy-Darling, J.; Choi, S.H.; Norstrom, E.M.; Sisodia, S.S.; Ismagilov, R.F. Plug-based microfluidics with defined surface chemistry to miniaturize and control aggregation of amyloidogenic peptides. Angew. Chem. Int. Ed. 2009, 48, 1487-1489. [CrossRef]

27. Kondapalli, S.; Kirby, B.J. Refolding of $\beta$-galactosidase: Microfluidic device for reagent metering and mixing and quantification of refolding yield. Microfluid. Nanofluid. 2009, 7, 275-281. [CrossRef]

28. Horrocks, M.H.; Tosatto, L.; Dear, A.J.; Garcia, G.A.; Iljina, M.; Cremades, N.; Dalla Serra, M.; Knowles, T.P.J.; Dobson, C.M.; Klenerman, D. Fast Flow Microfluidics and Single-Molecule Fluorescence for the Rapid Characterization of $\alpha$-Synuclein Oligomers. Anal. Chem. 2015, 87, 8818-8826. [CrossRef]

29. Arosio, P.; Müller, T.; Rajah, L.; Yates, E.V.; Aprile, F.A.; Zhang, Y.; Cohen, S.I.A.; White, D.A.; Herling, T.W.; De Genst, E.J.; et al. Microfluidic diffusion analysis of the sizes and interactions of proteins under native solution conditions. ACS Nano 2016, 10, 333-341. [CrossRef]

30. Herling, T.W.; O'Connell, D.J.; Bauer, M.C.; Persson, J.; Weininger, U.; Knowles, T.P.J.; Linse, S. A Microfluidic Platform for Real-Time Detection and Quantification of Protein-Ligand Interactions. Biophys. J. 2016, 110, 1957-1966. [CrossRef]

31. Saar, K.L.; Zhang, Y.; Müller, T.; Kumar, C.P.; Devenish, S.; Lynn, A.; Łapińska, U.; Yang, X.; Linse, S.; Knowles, T.P.J. On-chip label-free protein analysis with downstream electrodes for direct removal of electrolysis products. Lab. Chip 2017, 18, 162-170. [CrossRef] [PubMed]

32. Xia, Y.; Whitesides, G.M. Soft lithography. Annu. Rev. Mater. Sci. 1998, 28, 153-184. [CrossRef]

33. Unger, M.A.; Chou, H.P.; Thorsen, T.; Scherer, A.; Quake, S.R. Monolithic microfabricated valves and pumps by multilayer soft lithography. Science 2000, 288, 113-116. [CrossRef] [PubMed]

34. Hansen, C.L.; Skordalakest, E.; Berger, J.M.; Quake, S.R. A robust and scalable microfluidic metering method that allows protein crystal growth by free interface diffusion. Proc. Natl. Acad. Sci. USA 2002, 99, 16531-16536. [CrossRef] [PubMed]

35. Hansen, C.L.; Classen, S.; Berger, J.M.; Quake, S.R. A microfluidic device for kinetic optimization of protein crystallization and in situ structure determination. J. Am. Chem. Soc. 2006, 128, 3142-3143. [CrossRef] [PubMed]

36. Rho, H.S.; Hanke, A.T.; Ottens, M.; Gardeniers, H. Mapping of Enzyme Kinetics on a Microfluidic Device. PLoS ONE 2016, 11, e0153437. [CrossRef]

37. Marcus, J.S.; Anderson, W.F.; Quake, S.R. Parallel picoliter RT-PCR assays using microfluidics. Anal. Chem. 2006, 78, 956-958. [CrossRef] 
38. Tan, S.J.; Phan, H.; Gerry, B.M.; Kuhn, A.; Hong, L.Z.; Min Ong, Y.; Poon, P.S.Y.; Unger, M.A.; Jones, R.C.; Quake, S.R.; et al. A Microfluidic Device for Preparing Next Generation DNA Sequencing Libraries and for Automating Other Laboratory Protocols That Require One or More Column Chromatography Steps. PLoS ONE 2013, 8, e64084. [CrossRef]

39. Yang, Y.; Swennenhuis, J.F.; Rho, H.S.; Le Gac, S.; Terstappen, L.W.M.M. Parallel single cancer cell whole genome amplification using button-valve assisted mixing in nanoliter chambers. PLoS ONE 2014, 9, e155. [CrossRef]

40. Yang, Y.; Rho, H.S.; Stevens, M.; Tibbe, A.G.J.; Gardeniers, H.; Terstappen, L.W.M.M. Microfluidic device for DNA amplification of single cancer cells isolated from whole blood by self-seeding microwells. Lab. Chip 2015, 15, 4331-4337. [CrossRef]

41. Tatárová, Z.; Abbuehl, J.P.; Maerkl, S.; Huelsken, J. Microfluidic co-culture platform to quantify chemotaxis of primary stem cells. Lab. Chip 2016, 16, 1934-1945. [CrossRef] [PubMed]

42. Woodruff, K.; Maerkl, S.J. A High-Throughput Microfluidic Platform for Mammalian Cell Transfection and Culturing. Sci. Rep. 2016, 6, 23937. [CrossRef] [PubMed]

43. Maerkl, S.J.; Quake, S.R. A systems approach to measuring the binding energy landscapes of transcription factors. Science 2007, 315, 233-237. [CrossRef] [PubMed]

44. Garcia-Cordero, J.L.; Maerkl, S.J. Multiplexed surface micropatterning of proteins with a pressure-modulated microfluidic button-membrane. Chem. Commun. 2013, 49, 1264-1266. [CrossRef]

45. Bassett, D.C. Polymer spherulites: A modern assessment. J. Macromol. Sci. Phys. 2003, 42, 227-256. [CrossRef]

46. Waugh, D.F.; Wilhelmson, D.F.; Commerford, S.L.; Sackler, M.L. Studies of the Nueleation and Growth Reactions of Selected Types of Insulin Fibrils. J. Am. Chem. Soc. 1953, 75, 2592-2600. [CrossRef]

47. Biancalana, M.; Koide, S. Molecular mechanism of Thioflavin-T binding to amyloid fibrils. Biochim. Biophys. Acta Proteins Proteom. 2010, 1804, 1405-1412. [CrossRef]

48. Kuznetsova, I.M.; Sulatskaya, A.I.; Uversky, V.N.; Turoverov, K.K. Analyzing thioflavin t binding to amyloid fibrils by an equilibrium microdialysis-based technique. PLOS ONE 2012, 7, e30724. [CrossRef]

(C) 2020 by the authors. Licensee MDPI, Basel, Switzerland. This article is an open access article distributed under the terms and conditions of the Creative Commons Attribution (CC BY) license (http://creativecommons.org/licenses/by/4.0/). 